\title{
Establishing the Prevalence of Hypertension. Influence of Sampling Criteria
}

\author{
Sandra Costa Fuchs, Juliano G. Petter, Melissa C. Accordi, Vanessa L. Zen, A ntônio D. Pizzol-Jr, \\ Leila Beltrami Moreira, Flávio Danni Fuchs \\ Porto Alegre, RS - Brazil
}

\begin{abstract}
Objective - To compare the prevalence of systemic hypertension in two different populations: a representative sample of the adult urban population of Porto Alegre, and individuals who sought blood pressure measurement in a hypertension prevention and control campaign.
\end{abstract}

Methods - A cross-sectional study was carried out involving a representative sample of the adult urban population of Porto Alegre and a population sample obtained from a hypertension prevention and control campaign, which included all the individuals who sought the blood pressure assessment unit at the Hospital das Clinicas in Porto Alegre. The following parameters were investigated: history of hypertension, use of antihypertensive drugs, age, and sex. Adjustments for age and sex in the prevalence rates were performed to make them comparable.

Results - Hypertension prevalence, defined as values $\geq 160 / 95 \mathrm{mmHg}$ or treatment with antihypertensive drugs, was higher in the campaign sample (42\%) as compared with the population sample (24\%). Among those who were aware of their hypertensive condition and were under medication, 54\% of the campaign sample and $62 \%$ of the representative population sample maintained their pressure levels $<160 / 90 \mathrm{mmHg}$.

Conclusion - Prevalence rates of hypertension differed a lot in the campaign sample and in the representative population sample, showing that the sampling criterion may influence assessment of risk factors and bias the association between risk factors and health aggravations.

Keywords: hypertension, sampling, prevalence

Hospital de Clínicas de Porto Alegre - Faculdade de Medicina da UFRGS Mailing address: Sandra Costa Fuchs - Rua Ramiro Barcelos, 2600 - S/415 - 90035-003 - Porto Alegre, RS, Brazil

English version by Stela Maris C. Gandour
Risk quantification in medicine is based on epidemiological investigations performed in samples of individuals, out of which data for the whole population are inferred. This approach is justified because rarely can the whole population be studied, but it requires an appropriate sample to provide reliable results. In the clinical practice, availability of patients in hospitals and referral services often constitutes the sample by demand of patients or volunteers. Campaigns of disease prevention and detection are examples of samples of self-selected participants, who do not have a known probability of being included in the study.

However, more than theoretical, this question has a practical aspect, as is shown with the example of systemic hypertension. The high prevalence of hypertension in Brazil (between 14\% and 32\%) ${ }^{1-5}$ and its potential for control turn hypertension into the most important changeable risk factor for cardiovascular disease ${ }^{6}$. In the United States, data from the American Heart Association for 1997 estimated that the cost of attending and treating hypertensive patients was US $\$ 21.8$ billion. When adding reduction in productivity due to morbidity and mortality caused by hypertension, these costs were elevated by US $\$ 8.2$ billion ${ }^{7}$. These data show the magnitude of the error if preventive programs are based on estimates originating from nonrepresentative samples of the population.

In our study, we compared the prevalence of hypertension assessed in a hypertension prevention and control campaign with the prevalence obtained in the investigation of a representative sample of the same population of origin.

\section{Methods}

From 1996 to 1998, a cross-sectional study was carried out in a representative sample of the adult urban population of Porto Alegre, in which the prevalence of systemic hypertension was assessed among other parameters. The participants of the study were selected through a multiple-stage sample. Initially the boroughs of Porto Alegre were listed with their population estimated by the Instituto Brasileiro de 
Geografia e Estatística (IBGE - Brazilian Institute of Geography and Statistics). The individuals who should be included in each borough were randomly picked, and their number was proportional to the size of the borough. The census sectors of each borough were listed and the conglomerates taking part in the study were randomly picked. Each census sector was visited to check the distribution of dwellings, presence of hotels, hospitals, headquarters, or commercial facilities. Dwellings were selected in a systematic manner, ie, the first dwelling was randomly picked and then, following a clockwise direction, one after 10 dwellings was identified. In each dwelling, all individuals $\geq 18$ years of age were considered eligible. The resulting sample comprised 488 dwellings distributed in 27 census sectors of the IBGE. To calculate the size of the sample, 1 million individuals $\geq 18$ years of age were considered part of the population; estimating that $14 \%$ of this population had high blood pressure levels, with an accuracy of measurement of $2 \%$, we determined that 1,155 individuals should be studied. As this database aimed at testing hypotheses, the sample was enlarged, resulting in 1,174 individuals. Trained interviewers gathered information about the participants by applying pretested structured questionnaires in their dwellings. Blood pressure levels were measured in a standardized manner at the beginning and at the end of the interview. The mean of both measurements with correction for the brachial perimeter according to the formulae proposed by Maxwell ${ }^{8}$ was considered for analysis.

In another study carried out during the 1999 campaign of hypertension prevention and control, all 249 individuals who sought the blood pressure assessment unit in the Hospital das Clínicas in Porto Alegre were included (campaign sample). This medical unit was located at the entrance of the outpatient care clinics of the Hospital das Clínicas in Porto Alegre. This campaign sample comprised individuals of the general population who accepted the invitation that was aired in the media for measuring their blood pressure, along with other individuals who sought the outpatient care clinics of different specialties, their caretakers, and visitors in general. The participants refrained from smoking and drinking coffee in the 15-30 minutes preceding the interview, and they remained seated for at least 15 minutes while awaiting blood pressure measurement. The participants were interviewed and underwent blood pressure measurement in a standardized manner by trained personnel. In addition to blood pressure measurement, previous knowledge about hypertension, use of antihypertensive medication, age, and sex were investigated.

In both studies, blood pressure was measured with aneroid manometers, which were periodically calibrated taking mercurial manometers as references according to the Programa Nacional de Educação e Controle da Hipertenção Arterial ${ }^{9}$ guidelines (National Program on Education and Control of Hypertension) and of the Fifth Joint National Committee ${ }^{10}$. The first and fifth Korotkoff sounds were respectively considered the systolic and diastolic blood pressure levels. Systemic hypertension was defined as systolic blood pressure levels $\geq 140 \mathrm{mmHg}$ or diastolic blood pressure levels $\geq 90 \mathrm{mmHg}$, or belon this under the use of antihypertensive medication. A second classifying criterion was used with systolic blood pressure levels $\geq 160 \mathrm{mmHg}$ or diastolic blood pressure levels $\geq 95 \mathrm{mmHg}$, or use of medication, in order to reduce the potential for bias in measurement through the phenomenon of regression to the mean. The definition of hypertension was based on the diagnostic classification criteria recommended in the III Consenso Brasileiro de Hipertensão Arterial (III Brazilian Consensus on Hypertension) ${ }^{11}$. In the analysis of data, we used the distribution by sex and age in the population sample and the prevalence rates obtained in the campaign sample to calculate the standard prevalence rates through direct standardization ${ }^{12}$. Confidence intervals for the prevalence rates were calculated based on the formula: $\mathrm{P} \pm 1.96 \sqrt{(1-\mathrm{P} / \mathrm{N})}$; where $\mathrm{P}$ is the prevalence and $\mathrm{N}$ is the total number of individuals studied ${ }^{12}$. The chi-square test was used to analyze the statistical significance of the differences in prevalence rates in the 2 samples.

\section{Results}

Table I shows the characteristics of the 1,174 participants in the population sample (representative sample) and of the 249 individuals comprising the campaign sample, in which women prevailed ( $72 \%$ ). In the representative sample, women accounted for $56 \%$ of the individuals. The marked differences in age distribution of the participants included $44 \%$ of individuals under the age of 40 years and $22 \%$ of the individuals 60 or older than 60 years of age in the representative sample, as compared with $9 \%$ and $55 \%$, respectively, in the campaign sample.

Hypertension prevalence, family history of hypertension, frequency of treatment, and degree of hypertension control are shown in table II. Prevalence of systemic hypertension in the campaign sample was approximately two times higher than that in the population sample, independent of the diagnostic criterion used.

Applying the hypertension rates identified in the campaign sample to the distribution according to age and sex in the representative sample, we obtained standardized prevalence rates. Based on this direct standardization, the

\begin{tabular}{|c|c|c|c|c|c|}
\hline \multicolumn{6}{|c|}{$\begin{array}{l}\text { Table I - Demographic characteristics of the individuals studied in } \\
\text { the population and campaign samples }\end{array}$} \\
\hline & \multicolumn{2}{|c|}{ Population sample } & \multicolumn{2}{|c|}{ Campaign sample } & \multirow[t]{2}{*}{$\mathrm{p}$ value } \\
\hline & $\mathrm{N}$ & $\%$ & $\mathrm{~N}$ & $\%$ & \\
\hline Sex & & & & & $<0.00001$ \\
\hline Female & 659 & 56 & 180 & 72 & \\
\hline Male & 515 & 44 & 69 & 28 & \\
\hline Age (years) & & & & & $<0.000001$ \\
\hline 18-39 & 526 & 44 & 21 & 9 & \\
\hline $40-49$ & 230 & 20 & 51 & 20 & \\
\hline $50-59$ & 155 & 13 & 40 & 16 & \\
\hline$\geq 60$ & 263 & 22 & 137 & 55 & \\
\hline
\end{tabular}




\begin{tabular}{|c|c|c|c|c|c|}
\hline & \multicolumn{2}{|c|}{ Population sample } & \multicolumn{2}{|c|}{ Campaign sample } & \multirow[b]{2}{*}{$\begin{array}{c}\text { Standard prevalence } \\
(95 \% \mathrm{CI})\end{array}$} \\
\hline & $\mathrm{N}$ & $\begin{array}{l}\text { Prevalence } \\
(95 \% \mathrm{CI})\end{array}$ & $\mathrm{N}$ & $\begin{array}{l}\text { Prevalence } \\
(95 \% \mathrm{CI})\end{array}$ & \\
\hline \multicolumn{6}{|l|}{ SH } \\
\hline$\geq 140 / 90$ or medicine & 410 & $35 \%(30-40)$ & 179 & $72 \%(65-79) * * *$ & $58 \%(54-62)$ \\
\hline$\geq 140 / 90$ & 345 & $29 \%(25-34)$ & 147 & $59 \%(51-67) * * *$ & $45 \%(41-49)$ \\
\hline$\geq 160 / 95$ or medicine & 283 & $24 \%(19-29)$ & 144 & $58 \%(54-62) * * *$ & $42 \%(38-46)$ \\
\hline$\geq 160 / 95$ & 172 & $15 \%(10-20)$ & 79 & $32 \%(22-42) * * *$ & $25 \%(20-30)$ \\
\hline History of SH & 261 & $22 \%(17-27)$ & 130 & $52 \%(43-61) * * *$ & $38 \%(33-43)$ \\
\hline Treatment of SH & 177 & $68 \%(61-75)$ & 106 & $82 \%(75-89) * *$ & $68 \%(5-71)$ \\
\hline $\begin{array}{l}\text { Use of antihypertensive drug } \\
\text { and pressure }<140 / 90\end{array}$ & 64 & $36 \%(24-48)$ & 32 & $31 \%(15-47) *$ & $33 \%(28-38)$ \\
\hline $\begin{array}{l}\text { Use of antihypertensive drug } \\
\text { and pressure }<160 / 95\end{array}$ & 110 & $62 \%(53-71)$ & 65 & $61 \%(49-73) *$ & $54 \%(50-58)$ \\
\hline
\end{tabular}

samples became comparable; nevertheless, the prevalences of hypertension remained substantially higher in the campaign sample as compared with those of the representative sample. In the campaign sample, the standardized prevalence of hypertension, defined as blood pressure levels $>160 / 95 \mathrm{mmHg}$, was $25 \%$ as compared with $15 \%$ in the representative sample. The proportion of individuals with previous knowledge of their hypertensive condition also differed substantially between the samples. On the other hand, the frequency of use of antihypertensive medication was the same (68\%) for the participants of both samples.

Considering exclusively the individuals with prior knowledge of their hypertensive condition and using antihypertensive medication in both samples, we identified approximately the same proportion of people with controlled blood pressure according to the criterion of 140/ $90 \mathrm{mmHg}$. For the criterion of $160 / 95 \mathrm{mmHg}$, a slightly higher proportion of individuals was identified in the representative sample.

\section{Discussion}

The statistical basis of the test of hypotheses assumes that the use of probabilistic samples represents the population of origin. In epidemiological studies describing populations, samples are used, and the same principle of representativeness is assumed. However, this assumption is not always realized. The study by Korrick et al ${ }^{13}$ investigated a subsample of the Nurses' Health Study in the area of Boston, Massachusetts in the United States, to test the association between lead exposure and hypertension. The national study included a sample of 121,700 women, but in this substudy, out of the 689 potentially eligible women, only $43 \%$ agreed to participate ${ }^{13}$.

In our study, we compared the repercussion of the sampling criterion in the inclusion of participants in a study, where one sample was constituted by random selection through multiple stages and the other sample was formed by self-selected individuals, who sought a medical unit for blood pressure assessment on the national day for hypertension prevention and control. Analyzing the distribution of demographic characteristics, we identified a predominance of women and older individuals in the campaign sample. In another study ${ }^{14}$, differences in the distribution by sex and age between 2 samples, patients of the outpatient care clinic and employees of a department store in New York, were associated with variations in the prevalence rates of hypertension and diabetes. The greater number of women increases the prevalence of obesity and sedentary lifestyle and reduces the prevalence of abusive consumption of alcoholic beverages ${ }^{2}$. The inclusion of individuals older than 60 years of age suggests absence of formal work and a higher chance of hypertension ${ }^{3,5}$. Availability to seek a medical facility assumes, theoretically, a higher level of health care. In our study, the presence of these characteristics resulted in higher rates of hypertension in the campaign sample than in the representative sample. Comparisons between representative and nonprobabilistic samples show how bias in selection may distort results, such as increasing the prevalence of hypertension and diabetes ${ }^{14}$.

As the prevalence rate is a measure that summarizes the experience of an entire sample and does not discriminate heterogeneity among its members, we performed the direct standardization to make the samples comparable. However, even with standardization, prevalence rates of hypertension were higher in the campaign sample than in the representative sample. Using blood pressure levels $>160 /$ $95 \mathrm{mmHg}$ or antihypertensive medication, the prevalence of hypertension increased from $24 \%$ to $42 \%$.

These results show that in the campaign sample we studied a greater proportion of individuals with prior knowledge of their hypertensive condition. If the participants, in addition to hypertension also had other risk factors, the sampling criterion would not only change the distribution of characteristics of the participants but could also bias the magnitude of associations.

The findings have implications in different contexts of hypertension screening. Certainly, campaign samples lack representativeness to estimate the prevalence of aggrava- 
tions to health. The actual impact of a campaign as a mean of alerting and screening cases is hardly quantifiable. We observed that the experience in the clinical setting originating from the spontaneous demand of patients is closer to the findings detected in the campaign. Therefore, in this setting, concomitance of health aggravations is more common, leading to a distortion in their actual association. Representative studies lacking selection bias are the only ones capable of accurately measuring the prevalence of risk factors and diseases in communities.
In conclusion, the importance of sampling criteria for establishing estimates of prevalence of systemic hypertension has been shown. The implication of these findings should be considered in the frequent studies on cross-sectional delineation in our country, with samples of demand restricted by some diagnostic criteria. Clustering of characteristics investigated with diagnosis originating from the selection criterion may result from bias in selecting the sample of interest, the sample used in the comparison group, or from both.

\section{References}

1. Lolio CA, Pereira JCR, Lotufo PA, Souza JMP. Hipertensão arterial e possíveis fatores de risco. Rev Saúde Pública 1993; 27: 357-62.

2. Duncan BB, Schmidt MI, Polanczyk, Homirich CS, Rosa RS, Achutti AC. Fatores de risco para doenças não-transmissíveis em área metropolitana na região sul do Brasil. Prevalência e simultaneidade. Rev Saúde Pública 1993; 27: 143-8.

3. Fuchs FD, Moreira LB, Moraes RS, Bredmeier M, Cardozo SC. Prevalência de hipertensão arterial sistêmica e fatores associados na região urbana de Porto Alegre. Estudo de base populacional. Arq Bras Cardiol 1994; 63: 473-9.

4. Bloch KV, KleinCH, Silva NAS, Nogueira AR, Campos LHS. Hipertensão arterial e obesidade na Ilha do Governador - Rio de Janeiro. Arq Bras Cardiol 1994; 63: 17-22.

5. Piccini RX, Victora CG. Hipertensão arterial sistêmica em área urbana no sul do Brasil: prevalência e fatores de risco. Rev Saúde Pública 1994; 28: 261-7.

6. MacMahon S, Peto R, Cutler J, et al. Blood pressure, stroke, and coronary heart disease, I: prolonged differences in blood pressure: prospective observational studies corrected for the regression dilution bias. Lancet 1990; 335: 765-74.

7. American Heart Association. Economic cost of cardiovascular diseases. In:
1997 Heart and Stroke Statistical Update. Dallas, TX: American Heart Association, 1997.

8. Maxwell MH, Waks AU, Schroth PC, Karam M, Dornfeld LP. Error in blood pressure measurement due to incorrect cuff size in obese patients. Lancet 1982;2:33-5.

9. Ministério da Saúde. Normas Técnicas para o Programa Nacional de Educaçãoe Controle da Hipertensão Arterial (PNECHA). Brasília, Centro de Documentação do Ministério da Saúde, 1988.

10. Joint National Committee. The fifth report of the Joint National Committee on detection, evaluation, and treatment of high blood pressure. Arch Intern Med 1993; 153: 154-08

11. III Consenso Brasileiro de Hipertensão. Campos do Jordão (SP): Sociedade Brasileira de Hipertensão, 1998.

12. Kirkwood BR. Essential of Medical Statistics. London, Blackwell Scientific Publications, 1988

13. Korrick AS, Hunter DJ, Rotnitzky A, Howard h, Speizer F. Lead and hypertension in a sample of midle-age women. Am J Public Health 1999; 89:330-5.

14. Gerber LM, Wolf AM, Braham RL, Alderman MH. Effects of sample selection on the coincidence of hypertension and diabetes. JAMA; 1982: 43-6. 